\title{
A LUTA PELO DIREITO DE MORAR
}

Fermino Fechio* Erminia Maricato**

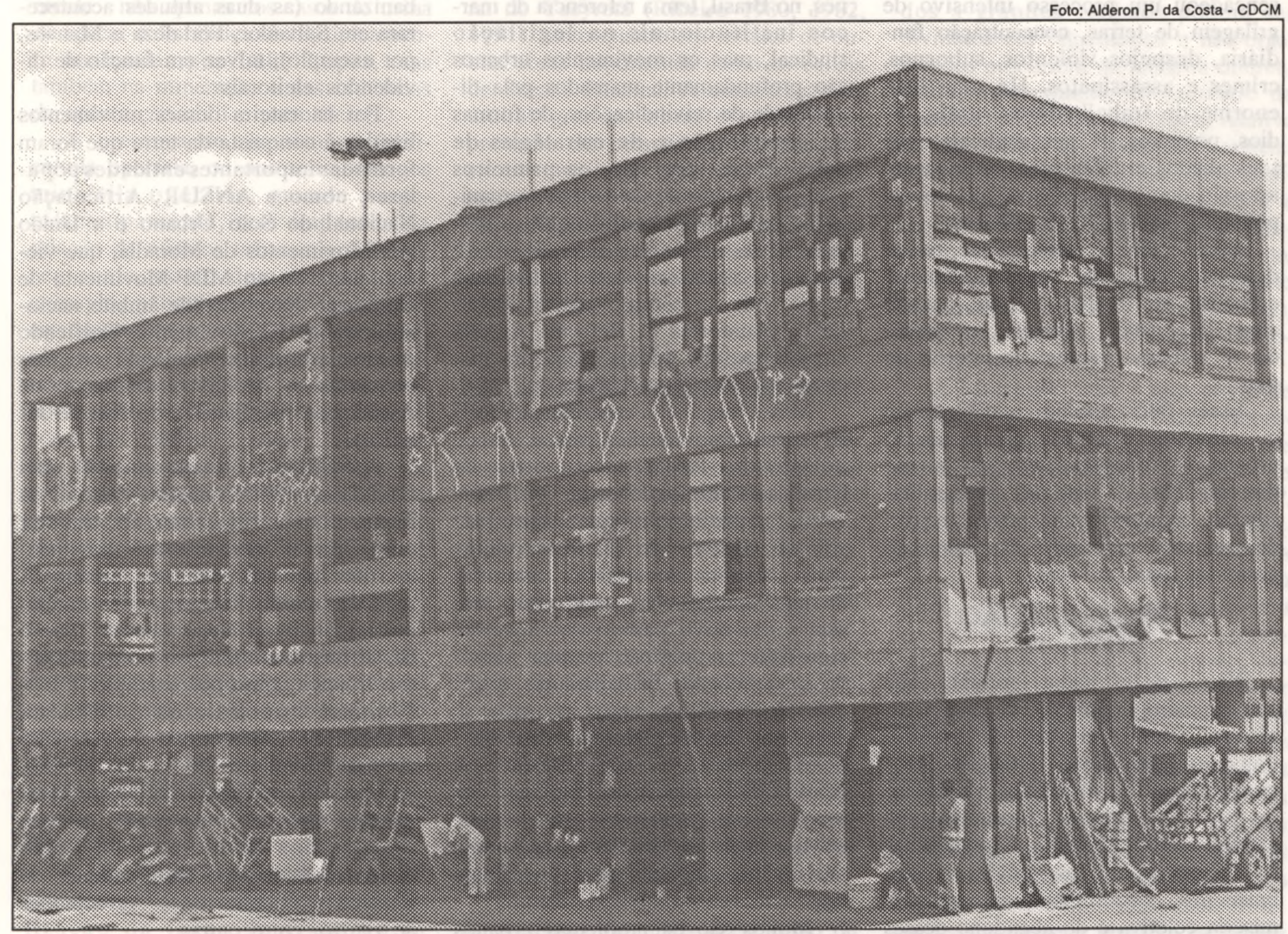

e em 1940 havia cerca de 13 milhões de brasileiros vivendo em cidades, o Censo Demográfico de 1980 já acusava a existência de mais de 82 milhões de habitantes urbanos, concentrados, sobretudo, nas capitais dos Estados, nos grandes centros e nas regiões metropolitanas.

Enquanto a população brasileira triplicava nesse periodo, a população urbana do país crescia em seis vezes: de $31 \%$ do total, passou para $68 \%$. A população rural declinou de quase 69\%, em 1940, para 32\%, em 1980.

Nessas últimas décadas, as nossas cidades foram literalmente invadidas por grandes contingentes populacionais. A Região Metropolitana de São
Paulo, por exemplo, pulou de aproximadamente 1.500 .000 habitantes, em 1940 , para 17.500 .000 , em 1990, população superior a de muitos países europeus e latino-americanos. As outras metrópoles brasileiras apresentaram, também, em menor escala, crescimento urbano excepcional.

Durante a década de $70,31 \%$ da população brasileira se deslocou de seu local de moradia e trabalho. Nos anos 80 , essa população aumentou para $33,6 \%$, perfazendo um total de 40 milhões de pessoas, aproximadamente, que mudaram de Município ou Estado.

As causas da explosão urbana são frequentemente atribuidas à modernização de nossa agricultura e ao fluxo migratório desordenado e intenso, que só nos anos 70, despejou 11 milhões de pessoas $\mathrm{em}$ nove área metropolitanas do país, das quais 2,7 milhões só na Região Metropolitana de São Paulo.

É certo, porém, que outros fatores, bem mais eficazes, atuam há muito tempo, como verdadeiros mecanismos de expulsão de trabalhadores rurais, posseiros e pequenos proprietários, do campo para a cidade.

Com o golpe de 64 , sobreveio uma repressão brutal contra as lideranças das ligas camponesas e sindicatos rurais, ao mesmo tempo em que o governo promulgava o Estatuto da Terra, com o intuito de desmobilizar os movimentos reivindicatórios de reforma agrária. 
Com a criação da SUDAM (Superintendência de Desenvolvimento da Amazônia) e do Banco da Amazônia, implantou-se a nefasta politica dos incentivos fiscais que, além de um grande desperdício de recursos públicos, desencadeou um processo intensivo de grilagem de terras, concentração fundiária, despejos violentos, subornos, crimes e assassinatos. Há uma lista enorme de trabalhadores rurais, indios, posseiros, líderes sindicais e de seus aliados e defensores, brutalmente assassinados por jagunços, pistoleiros, policiais, fazendeiros e grileiros.

Essa violência, infelizmente, recrudesceu na chamada "Nova República" e persiste até os dias de hoje, quando ainda se constata, inclusive, a existência de trabalho escravo no interior do país.

Esses fatos ajudam a entender o crescimento vetiginoso da população urbana e o consequente agravamento das condições de vida nas cidades brasileiras, compondo um quadro terrível de exclusão e segregação da população nesses espaços urbanos.

\section{A ORGANIZAÇĀO POPULAR}

Não é de estranhar, portanto, que nesse quadro dramático, de tantas carências sociais (habitação, saúde, transporte, educação...) nascessem e proliferassem os chamados movimentos populares urbanos, formando uma extensa rede de reuniões e assembléias no cinturão pobre das grandes cidades brasileiras, decodificando as causas da miséria coletiva e do abandono desses bairros para, num segundo momento, exigir do Estado o atendimento de suas necessidades comuns, o respeito aos direitos coletivos e o reconhecimento da condição de cidadãos.

Interessante destacar a profunda autonomia que esses movimentos apresentam, em sua origem, em relação ao espaço institucional, ressalvada, apenas, a presença importante da igreja católica. Mesmo nos bairros onde não se podia contar com o espaço físico da igreja, os edifícios do poder público não eram identificados como locais apropriados para as reuniões que, nesse caso, se realizavam em residências diminutas ou ao ar livre. $\mathrm{O}$ edifício público era visto como área estranha ao universo de identidade popular.
Como esses movimentos se formaram contra o Estado, como bem assinala Chico de Oliveira, o selo do Estado era a marca que conferia ao equipamento público um estatuto estranho.

O movimento operário e camponês, no Brasil, tem a referência de mar$\cos$ institucionais na legislação sindical, mas os movimentos urbanos são profundamente marcados pela diversidade de reivindicações, de formas de organização e de estratégias de ação. Talvez por isso, os primeiros avançaram mais ao nível de sua organização política nacional do que os movimentos urbanos, cuja unidade estrutural ainda carece de maturidade, o que pode ser comprovado na consolidada plataforma de Reforma Agrária em relação aos pontos ainda em discussão, da Reforma Urbana.

Mas é inegável a contribuição decisiva desses movimentos para o avanço político das forças de esquerda, no Brasil, nos últimos 15 anos. De 1975 a 1990 , o cenário político brasileiro passou da vigência de ditadura militar para a abertura democrática, assumindo uma configuração onde estão presentes um novo partido de esquerda, com forte composição popular massiva, o Partido dos Trabalhadores, e três centrais operárias, entre as quais se destaca a Central Única dos Trabalhadores, oriunda de uma entidade, a ANAMPOS-Associação Nacional dos Movimentos Populares - que incluia, em seu início movimentos populares e movimentos sindicais na mesma plenária.

Muitos são os problemas urbanos que atingem os trabalhadores em seu cotidiano: condições e custo dos transportes, falta de saneamento básico e consequentes epidemias, enchentes, desmoronamentos, etc. Nenhum desses problemas, entretanto, gera a mobilização e a organização que alcançou o movimento de moradia, em que pese ainda a falta de maturidade de uma proposta global de Reforma Urbana.

As lutas pioneiras pela regularização dos loteamentos clandestinos, pelas melhorias coletivas nas favelas, ou à luta dos mutuários do SFH que alcançou repercussão nacional, seguiram-se, nos anos 80, movimentos em todo o país por ocupações de terras vazias. A este movimento, ora organizado, ora quase espontâneo, o Estado respondeu ou com repressão (em 1987, Adão da Silva foi morto pela polícia militar quando participava de acampamento dos Sem-Terra na zona leste de São Paulo), ou com passividade ou até com complacência, regularizando e urbanizando (as duas atitudes aconteceram em Salvador, Fortaleza e Manaus, por exemplo), talvez em função de dividendos eleitorais.

Foi na esteira desses movimentos ligados à conquista da terra que foram formadas importantes entidades populares, como a ANSUR, Articulação Nacional do Solo Urbano e a União dos Movimentos de Moradia, que vieram juntar-se ao MDF-Movimento de Defesa do Favelado (de âmbito nacional), ao MUF-Movimento Unificado de Favelas (âmbito São Paulo e regiões próximas) e FAFERJ (federação de Associações de Favelas do Rio de Janeiro).

A ANSUR foi criada em 1984, com a ajuda da CPT-Comissão Pastoral da Terra, com a finalidade de articular assessorias e lideranças dos movimentos que lutavam pela terra urbana. A ANSUR reuniu lideranças das entidades regionais ou locais que em todo o Brasil buscavam unificar os movimentos urbanos como por exemplo: CBBComissão de Bairros de Belém, FAMERJ- Federação de Associações de Moradores do Rio de Janeiro, AUAMPA E FRACAB respectivamente União das Associações de Moradores dos Municípios de Porto Alegre e Federação Riograndense de Centros Comunitários e Associações de Bairro, entre outras.

Teve destaque a ação da ANSUR na tramitação da emenda constitucional de iniciativa popular de Reforma Urbana, apresentada também com outras entidades populares e profissionais à constituinte nacional em $1987 \mathrm{e}$ subscrita por 160.000 eleitores de todo o país.

Em 1990, as entidades que se reuniam em torno da ANSUR criaram o Movimento Nacional pela Luta da Moradia, em encontro nacional, na cidade de Goiânia.

A União dos Movimentos de Moradia teve origem nos bairros da Zona Leste de São Paulo e se expandiu regionalmente e nacionalmente mantendo uma linha de entidade de massa. 
Foram os mutirões de moradia desenvolvidos no Uruguai a fonte inspiradora de um importante salto de qualidade nas propostas elaboradas pelos movimentos de São Paulo (inicialmente na região sul de São Paulo e depois pela União) e que por sua vez inspiraram o programa Funaps Comunitário da gestão petista da Prefeitura de São Paulo.

A União dos Movimentos de Moradia teve a iniciativa de chamar a primeira caravana rumo ao governo federal em 1988, para reivindicar recursos para financiamento à moradia. Esta caravana contou com 8 ônibus que partiram de São Paulo (7) e Pernambuco (1). Em 1989 uma caravana reuniu 20 ônibus (mais de 1.000 pessoas) e em 1990 a terceira caravana levou aproximadamente 40 ônibus lotados de manifestantes a Brasília.

Mas a iniciativa popular mais importante e a proposta mais avançada dos movimentos de moradia foi sem dúvida o projeto do Fundo Nacional de Moradia Popular, levado ao Congresso Nacional em 1991, na 4- Caravana, por 4.000 militantes dos movimentos de moradia de todo o Brasil, que lotaram 52 ônibus.

O projeto foi subscrito por mais de 800.000 pessoas e seu conteúdo busca assegurar recursos financeiros administrados democraticamente para a produção ou melhorias de moradias com participação popular.

Este projeto de lei conseguiu reunir, não sem dificuldades,os principais movimentos de moradia e de luta pela Reforma Urbana de todo o país.

No bojo da discussão da emenda constitucional de iniciativa popular de Reforma Urbana, foi criado o Fórum Nacional de Reforma Urbana, em 1988 , com entidade nacionais e regionais de todo o pais, contando com participação expressiva da universidade. Foi elaborada pelo Fórum uma Carta de Princípios de Reforma Urbana (1989), um substitutivo do Prejeto de Lei de Desenvolvimento Urbano, apresentado no Congresso Nacional pela deputada federal Lurdinha Savignon (1990). Durante a elaboração do Projeto de Lei do Fundo Nacional de Moradia, o Fórum ganha novo fôlego e se rearticula em torno da questão ambiental, visando interferir na reunião paralela das ONGs por ocasião da

ECO-92. Participam do Fórum Nacional da Reforma Urbana as seguintes entidades: FASE, POLIS, FNA, FNE, AGB, ANSUR, SERJ, CONAM, PRCENTRAL DE MOVIMENTOS POPULARES, MOVIMENTO NACIONAL PELA LUTA DA MORADIA, UNIÃO DOS MOVIMENTOS DE MORADIA, CONSENGE, IBAM, FAMERJ, IBASE, CDDH, CNS e CUT.

\section{OS MOVIMENTOS DE MORADIA EM SĀO PAULO}

São Paulo tem aproximadamente 800 mil pessoas morando em favelas e 3 milhões morando em cortiços, além de mais de 2,4 milhões em habitações precárias, em loteamentos irregulares, quase sem nenhuma infra-estrutura urbana.

É facilmente compreensível, pois, que a luta pela moradia popular, na cidade, adquirisse a importância que teve ao longo desse processo intenso de expansão urbana que São Paulo viveu nas últimas décadas. Os direitos dos moradores de aluguel, e o acesso ao lote de terreno, a garantia da terra, as ocupações, o acesso à habitação, a regularização do loteamento, a urbanização das favelas, a disputa por uma vaga em prédios da COHAB, os mutirões, a auto-construção, foram todos eixos de organização popular, com um mesmo pano-de-fundo: a solução do problema de moradia.

\section{LOTEAMENTOS CLANDESTINOS}

Esse movimento, surgido na Zona Sul de São Paulo, em meados dos anos 70 , com o objetivo de regularizar a situação jurídica dos loteamentos junto à Prefeitura e aos Cartórios de Registro de Imóveis e assegurar a obtenção das escrituras pelos moradores, rapidamente ganhou notoriedade e espalhou-se por toda a cidade. Todas as edificações nesses loteamentos eram também irregulares, sujeitando os moradores a multas e penalizações.

A Prefeitura foi obrigada a rever suas rotinas administrativas e criar mecanismos especiais de regularização desses terrenos. Em nível federal foi promulgada uma nova lei para disciplinar os parcelamentos do solo e coibir a ação dos loteadores e imobiliárias inscrupulosos, a Lei 6766, de 19.12.1979.

Reconhecendo a importância histórica que o movimento teve no desenvovimento das lutas pelo acesso, posse e propriedade da terra, Maria da Glória Gohn, no seu livro "Movimentos Sociais e luta pela moradia" (Edições Loyola, São Paulo, 1991) assinala que "ele foi o estopim de uma crise que revelou as condições de habitação e sobrevivência de grande parcela das classes populares".

Hoje em dia, com a regularização da maior parte dos loteamentos envolvidos, o Movimentos praticamente desapareceu em São Paulo, sobrevivendo apenas nos bairros pendentes de solução, como reivindicação localizada.

\section{FAVELAS}

É histórica, também, a luta de resistência da população favelada para assegurar a posse precária de terrenos ocupados, convivendo com a ameaça sempre presente do despejo que, na maioria dos casos, acabava se consumando.

Com a proliferação e o inchaço das favelas, cresceu também a necessidade de organização. No início, eram reivindicações por água e luz. Logo, porém, percebeu-se que o fundamental era $o$ lugar para permanecer na terra.

MDF e MUF são siglas rapidamente identificadas pelos favelados.

O Movimento de Defesa do Favelado-MDF foi o pioneiro (1978), e nasceu em meio às bases da igreja católica, fortemente apoiado pela Frente $\mathrm{Na}$ cional do Trabalho, atuando não só na capital, mas também no ABC e outras cidades, contra os despejos e remoções de favelas.

O MUF-Movimento Unificado de Favelas surgiu já no início dos anos 80 , em torno das bandeiras de taxa mínima de água e luz, financiamento de materiais de construção e uma proposta inovadora e criativa - a concessão de direito real de uso - que, posteriormente correu todo o país, teve acolhida na Assembléia Nacional Constituinte e foi inserida no texto constitucional de 88 . Com a concessão, em outras palavras, os favelados reivindicavam apenas a posse coletiva dos terrenos públicos ocupados (a propriedade continuaria 


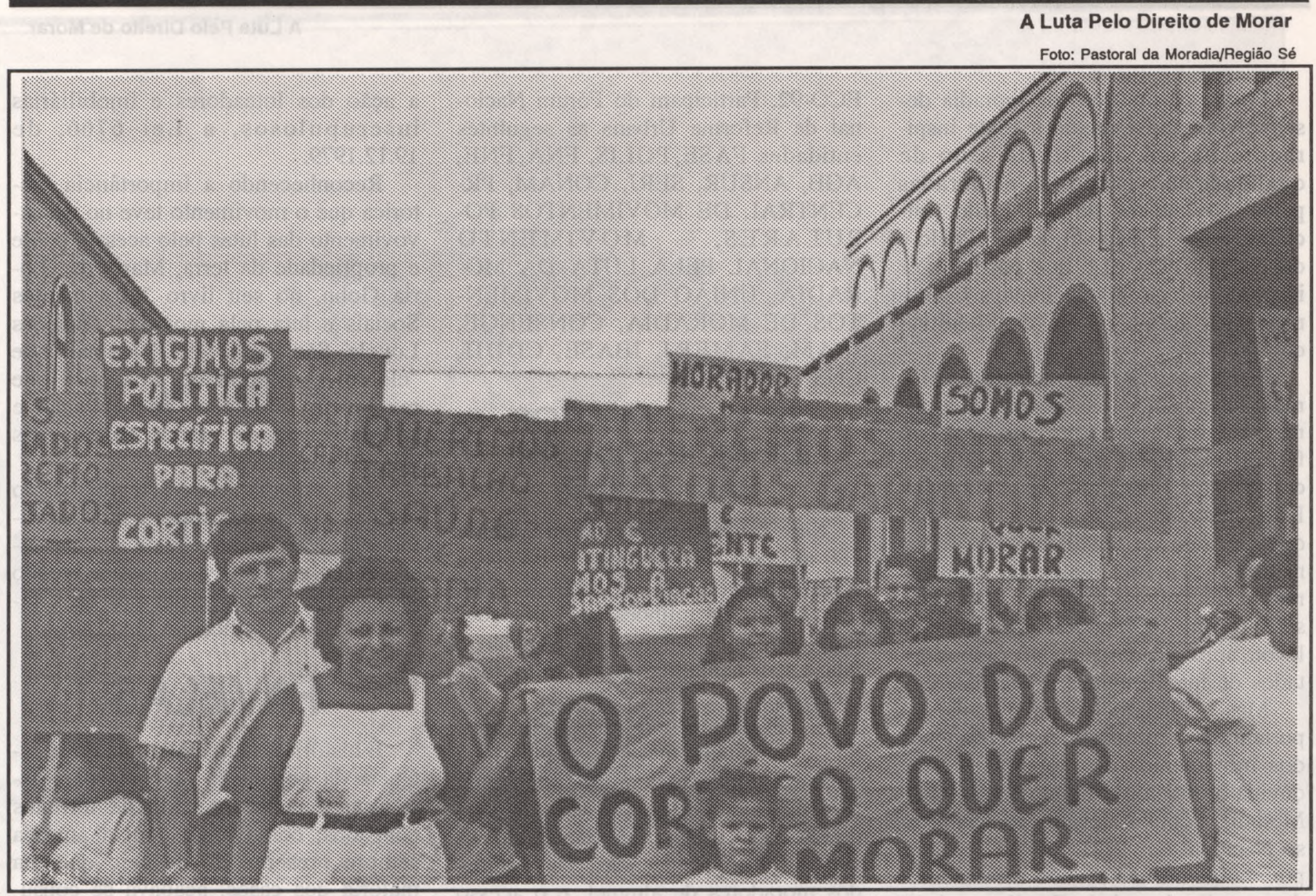

com a Prefeitura), pelo prazo de 90 anos, gratuitamente.

A idéia fora apresentada pela primeira vez em 1978, na igreja da Cidade Dutra, zona sul da cidade, numa assembléia de favelados ameaçados de despejo pela Prefeitura, como alternativa à proposta de compra dos terrenos.

Comprar como, se ninguém tinha renda alguma? A concessão resolvia esse impasse: podia ser gratuita.

A proposta, novidade absoluta, demorou para ser assimilada pelos favelados (a idéia de comprar, de virar proprietário, culturalmente é muito forte entre os brasileiros), mas continuou sendo discutida, para ser retomada pelo MUF, em 83, com muito mais força.

O Projeto de Lei foi apresentado à Câmara, durante o governo Mário Covas, mas não prosperou, devido a forte reação do governo municipal à idéia da concessão. A proposta vingou, no entanto, em municípios vizinhos, como Diadema, por exemplo, que logo aprovou projeto semelhante, longamente discutido com os favelados.
No governo Luiza Erundina o projeto foi reapresentado à Câmara, onde passou por modificações eliminando a proposta da concessão e abraçando a proposta de compra e venda trazida por outros movimentos e partidos como forma de buscar sua aprovação. Mesmo assim, até agora (maio/92), nada foi aprovado.

Enquanto isso, o Movimento tem batalhado pela urbanização das favelas - construção de muros de arrimo, rede de esgotos, canalização dos córregos, reorganização das vias de circulação, etc. Em alguns casos, a Prefeitura fornece o material e o projeto e a população, a mão-de-obra. Em outros, as obras são realizadas por empreiteiras. Em ambos os casos, porém, o projeto físico tem que obter o concordância dos moradores.

\section{CORTIÇOS}

Apesar do grande contingente de pessoas que moram em cortiços, em São Paulo, sempre foi muito débil sua organização. Os poucos núcleos mobilizados pegaram carona no MUF, aliando-se aos favelados. Recentemente (1991), formaram uma nova entida- de, a ULC- União das Lutas dos Cortiços, que tem articulado moradores das regiões Sé, Sudeste e Leste da cidade.

Junto ao Governo Municipal tem trabalhado na forma de convênios, viabilizando financiamentos para aquisição e reforma dos antigos casarões, para dotá-los de condições de habitabilidade.

\section{MUTIRŌES}

O movimento de moradia, em São Paulo, desde o final dos anos 80 , vive uma outra etapa bastante diferente daquela em que a preocupação principal se traduzia em reivindicações por água e luz, regularização fundiária e garantia da posse da terra.

O momento, agora, é o de participação nas decisões e controle da produção de unidades habitacionais, o que tem feito proliferar um grande número de associações de moradores para resolver o problema de moradia de um grupo, através de mutirões comunitários, em sistema de co-gestão entre essas associações e o poder público.

A autoconstrução sempre foi prática corrente nas cidades brasileiras, 


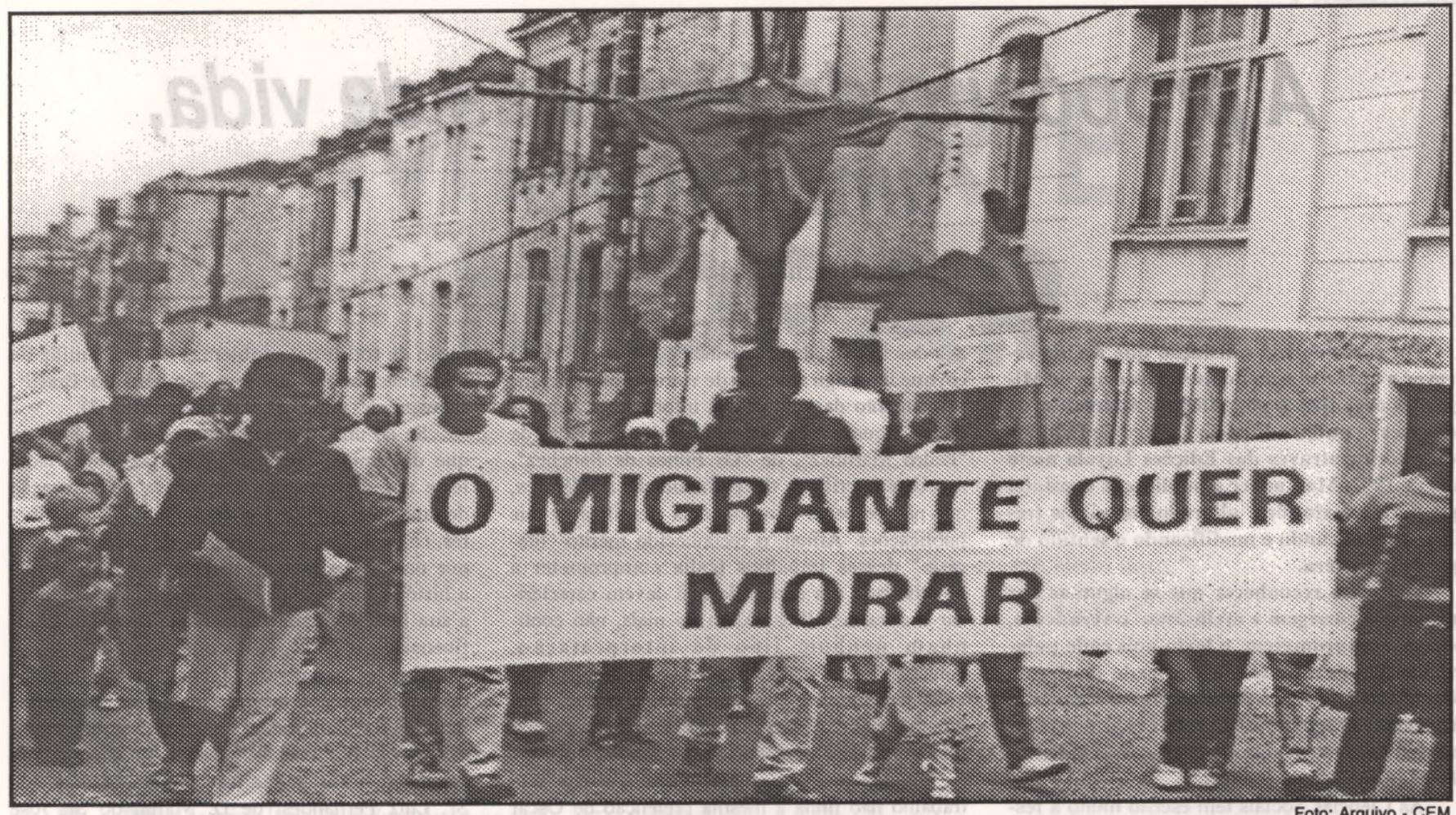

como forma alternativa para a população de baixa renda, tradicionalmente excluída dos programas habitacionais oficiais, resolver seu problema de moradia.

A cidade assistiu, na última década, a uma grande onda de ocupações coletivas de terrenos ociosos na periferia. Da reação inicial de recorrer ao despejo dos ocupantes, até com certa violência, na maioria dos casos o Poder Público evoluiu, posteriormente, para uma atitude de negociação. Garantiu assim a permanência de alguns grupos nas áreas ocupadas, motivou desapropriações de área litigiosas, financiou materiais necessários e favoreceu a construção de moradias pelo sistema de mutirões. A participação do povo, entretanto, se limitava ao fornecimento da mão-de-obra.

Com o avanço da organização popular, as Associações conseguiram participar das decisões arquitetônicas dos projetos, estabelecer o processo de trabalho a ser empregado e acompanhar os aspectos financeiros da obra.

Assim, na atual Administração $\mathrm{Mu}$ nicipal, a Prefeitura faz convênio com a Associação dos Moradores para o repasse de recursos financeiros para a construção de um projeto apresentado e previamente aprovado por eles.
A gestão dos recursos e a construção é feita pela Associação, que recebe o financiamento parceladamente, a cada etapa da obra concluída. O financiamento permite pagar assistência técnica (em geral, arquitetos e engenheiros militantes, da confiança dos moradores) e uma porcentagem da mão-de-obra, sendo a maior parte desta fornecida pelos futuros moradores, segundo regras estabelecidas por eles mesmos na divisão do trabalho.

Com isso, o custo das moradias, a qualidade da obra e a produtividade têm sido excepcionais, com notável economia de mão-de-obra, no seu gerenciamento, nas compras de material, feitas pela própria Associação, e na ausência de desperdícios no canteiro da construção.

Esses conjuntos habitacionais construídos por autogestão têm apresentado inúmeras vantagens de custo, qualidade do produto e produtividade sobre os conjuntos construídos por empresários contratados pelo governo.

Essas experiências ensejaram a criação, em São Paulo, do Conselho Municipal de Habitação Popular, para acompanhar e fiscalizar a política habitacional do Município. Esse Conselho, cujo estatuto foi discutido por 80 entidades civis, tem seus membros escolhidos por voto secreto. O projeto de lei encontra-se na Câmara Municipal de São Paulo.

\section{CONCLUSÃO}

A trajetória descrita mostra o avanço dos movimentos de moradia rumo à mudança de leis que impedem o atendimento às suas reivindicações ou a criação de outras com a mesma finalidade. Os embates com o legislativo estão em seu início e já revelam as dificuldades que os movimentos deverão superar para assegurar vitórias em relação à regularização da posse da terra aos favelados, em relação ao Conselho Popular de Habitação, em relação ao Fundo Nacional de Moradia Popular, entre outros. Apesar das dificuldades, o caminho para a Reforma Urbana está sendo aberto, sem dúvida, através das lutas cotidianas pelo direito de morar.

\section{* Fermino Fechio é advogado, assessor dos Movimentos Populares de Moradia, vereador pela bancada do PT na Câmara Municipal de SP e de 89 a 92 foi Secretá- rio Municipal da Administração.}

** Ermínia Maricato é arquiteta e secretária da Habitação e Desenvolvimento Urbano do Município de São Paulo. 